\title{
First experience with a new technique: Portable gamma camera usage for sentinel lymph node identification in a patient with breast cancer
}

\author{
Zehra Pınar Koç1, Pınar Pelin Özcan Kara1', Mustafa Berkeșoğlu², Tamer Akça ${ }^{2}$
}

ABSTRACT
$\begin{aligned} & \text { The newest development in sentinel lymph node imaging is portable gamma probe imaging. In this case report, } \\ & \text { results of all SLN detection methods were analyzed. The patient was imaged using a large field-of-view gamma } \\ & \text { camera with additional blue dye administration and intraoperative localization of sentinel lymph node using both } \\ & \text { gamma probe and portable gamma camera was performed. In this case report, the value of additional portable } \\ & \text { gamma camera imaging was analyzed. } \\ & \text { Keywords: Breast cancer, gamma probe, portable gamma camera, sentinel lymph node }\end{aligned}$

Cite this paper as: Koç ZP, Özcan Kara PP, Berkeşoğlu M, AkçaT. First experience with a new technique: portable gamma camera usage for sentinel lymph node identification in a patient with breast cancer. Turk J Surg 2018; 34: 57-59.

'Department of Nuclear Medicine, Mersin University School of Medicine, Mersin, Turkey

2Department of General Surgery, Mersin University School of Medicine, Mersin, Turkey

Address for Correspondence Zehra Pınar Koç e-mail:zehrapinarkoc@gmail.com

Received: 19.06.2016 Accepted: 10.10 .2016

(C) Copyright 2018 by Turkish Surgical Association

Available online at www.turkjsurg.com

\section{INTRODUCTION}

Preoperative physical examination, ultrasonography, computed tomography/magnetic resonance imaging are initially performed on evaluation of axilla in patients with breast cancer. Additionally, invasive methods like fine needle aspiration biopsy or Tru-cut biopsy may be necessary in some patients. However, sentinel lymph node (SLN) analysis is the accepted method for staging axillary lymph nodes (1). Despite all the advances in the field of imaging for oncology (Positron emission tomography imaging or magnetic resonance imaging), SLN imaging continues to be the most important modality in axillary staging in early breast cancer patients with radiopathologically negative axillary lymph node status ( 2 , 3). Intraoperative gamma probe applications have become a standard procedure in SLN identification during the surgery (1). There are some discussions about the necessity of preoperative gamma camera imaging; however, scintigraphy imaging provides the exact number of lymph nodes, and the additional lymph nodes may be observed outside the axillary region (4). Portable gamma camera imaging is a new development that provides intra-operative images of the injection site and possible SLNs. The expectations from this new modality in SLN imaging are finding out additional lymph nodes, confidence regarding the complete excision of all SLNs, and ruling out possible unexpected lymph nodes like internal mammarian lymph nodes if preoperative gamma camera imaging was not performed (5). There are limited numbers of studies concerning the performance of portable gamma camera in SLN imaging for breast cancer patients (6). SLNs initially discovered by both of the gamma probe and gamma camera in combined manner after while sentinel nodes were removed via gamma probe then axilla was checked with gamma camera for unrevealed nodes (6).

In this case, the influence of all SLN imaging methods was demonstrated in the reported patient. We aimed to find out the effectivity of portable gamma camera in SLN imaging.

\section{CASE PRESENTATION}

A 68-year-old female patient with anamnesis of breast lesion identified previously, which was diagnosed as malignant, visited our hospital and left mastectomy and additional SLN excision was planned.The patient had palpable left breast tumor without palpable lymph node in the axillary region (clinically N0). Prior to the surgery and after the informed consent was obtained, gamma camera imaging for SLN identification was performed by subdermal administration of $1 \mathrm{mCi}(37 \mathrm{MBq}$ ) nanocolloidusing a double-head SPECT gamma camera in a dynamic manner in anteroposterior projection. The injection was administered in the Nuclear Medicine Department about $1 \mathrm{~h}$ prior to the surgery. Single SLN was identified in left axilla by scintigraphy. Additional blue dye administration was performed. In the operating room prior to surgery, activity of injection site and additional lymph node in left axilla was localized by portable gamma camera (Crystal Cam; with technical specialties as follows; dimensions: $65 \times 65 \times 180 \mathrm{~mm}$; detector: CdZnTe, 16×16=256 Pixel; detector dimensions: 39.06×39.06×5mm; energy range: 45-250keV; energy resolution: $<6 \%$ at $122 \mathrm{keV},<5.5 \%$ at Tc-99m) (Video 1 ). Left simple mastectomy and SLN dissection were planned for the patient. A clinician from Nuclear Medicine Department was in the operating room; one of surgeons performed the dissection with the guidance of gamma probe. During the opera- 


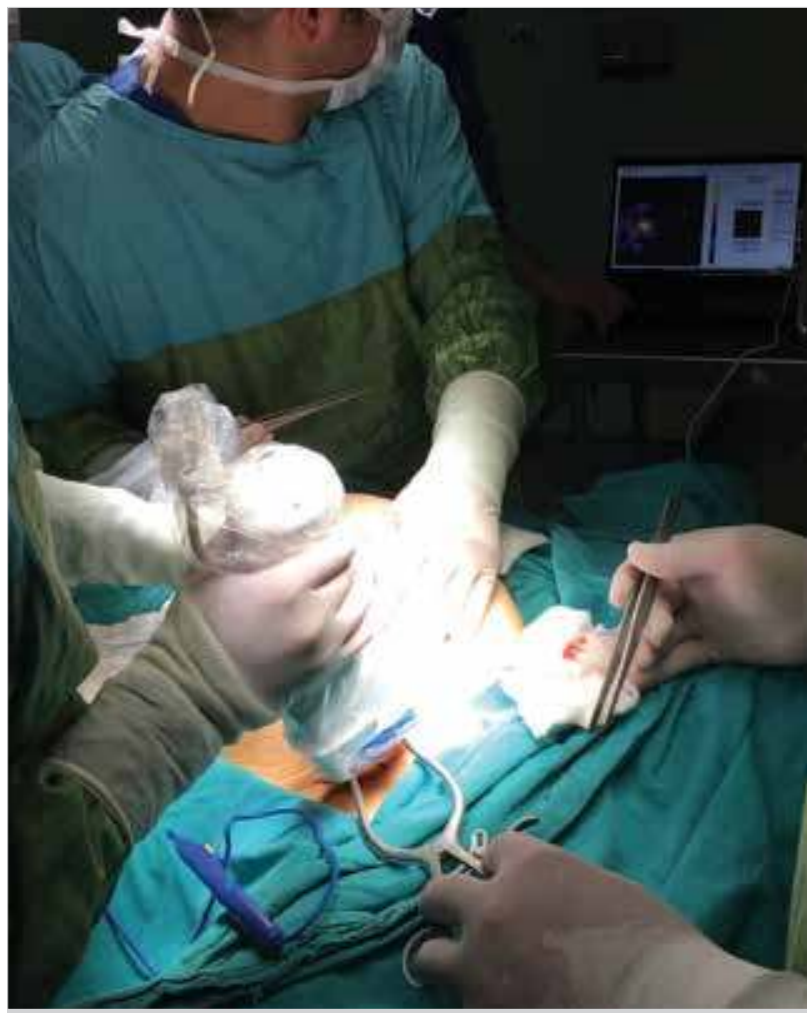

Figure 1. Exploration of sentinel lymph node using portable gamma camera

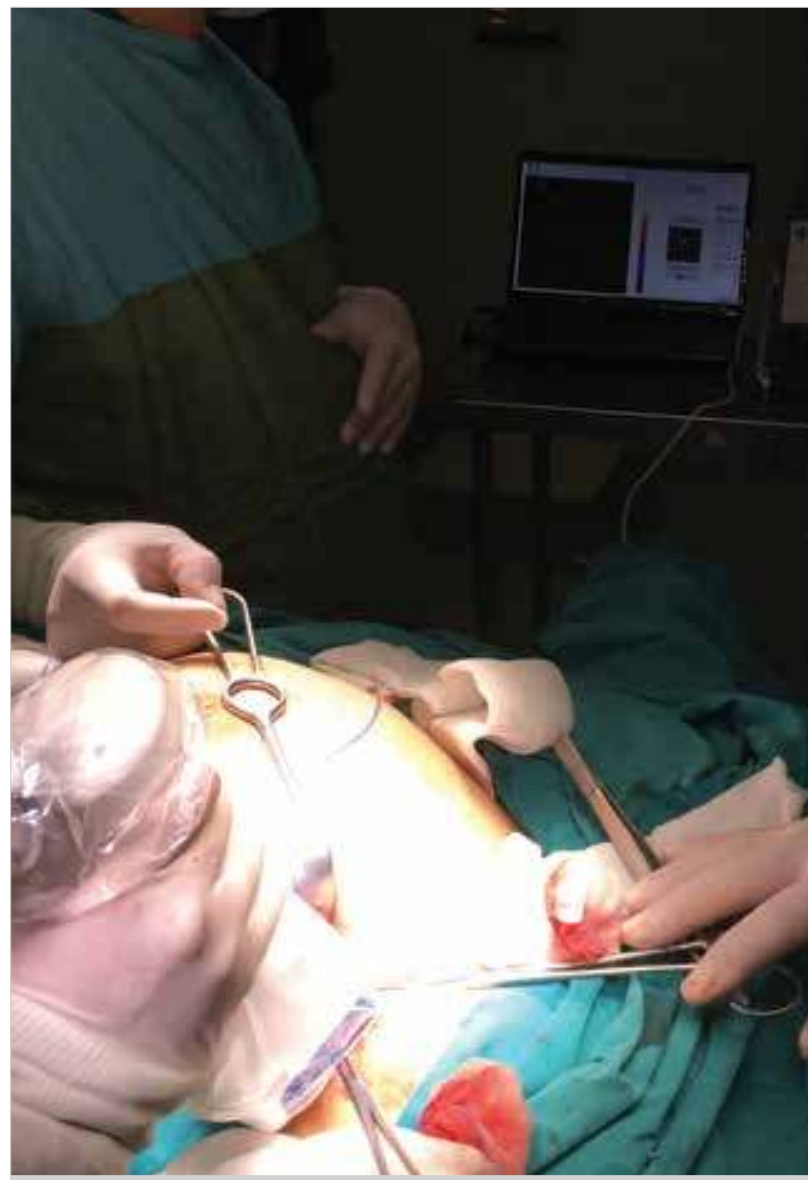

Figure 2. After the clarification of the axillary region, absence of activity anywhere else was verified using tion, simultaneous evaluation of SLN by both portable gamma camera (Figure 1) and gamma probe pointed out the same lesion that was excised after awhile and was proved to be the target SLN by both devices.Clarification of the axillary region and absence of activity anywhere else was verified using the portable gamma camera (Figure 2). The identification and excision of the lymph node took $15 \mathrm{~min}$. Frozen section analysis of the SLN did not reveal any tumor-bearing lymph node and additional left mastectomy specimen showed a $2 \mathrm{~cm}$ invasive ductal carcinoma lesion. Patient had an eventless postoperative period with no complications.

\section{DISCUSSION}

In patients with NO clinical nodal status, it is possible to perform SLN dissection instead of axillary dissection, which is a morbid procedure (1). Radionuclide identification of the SLN and radioguided surgery is the method of choice in most of the centers like ours.Recent advances have improved SLN detection rates and provided easier identification of SLNs in especially difficult cases that may require additional SPECT/CT imaging, an imaging modality which helps with anatomical information in addition to planar gamma camera imaging and intraoperative gamma probe localization (7). In some cases, identification of SLNs may be challenging, despite the injection of blue dye and preoperative scintigraphy imaging and gamma probe localization, requiring longer time for SLN excision (8). The possible difficulties in SLN imaging may be in transit nodes, internal mammary lymph nodes, and lymph nodes in close proximity to the injection site (9). Soluri et al. (10) considered portable gamma camera imaging beneficial in $27 \%$ of their patients. Vermeeren et al. (11) reported additional $24 \%$ improvement in SLN detection rate by application of portable gamma camera. Vidal-Sicard et al. (12) found that portable gamma probe might identify SLN in $88 \%$ of cases. Although previous authors report about 10 min of prolonged operation time, in our experience, we did not observe additional time delay to complete the operation (13). The identification and excision of SLN took $15 \mathrm{~min}$. CardonaArbonies et al. (14) emphasized the fact that there might be additional sentinel lymph nodes other than the preoperative scintigraphy because of different positions of the patient during the surgery and during the scintigraphy, and they observed two cases with additional lymph nodes depicted after the excision because of remaining activity observed using the portable gamma camera.

In order to obviate the need for axillary dissection, it is advised to achieve an identification rate of $>90 \%$ and a false negativity rate of $<5 \%$ according to recent guidelines (5). However, a false negativity rate below $5 \%$ is considered difficult according to the literature (5). Goni Girones et al. (5) reported an increase of $1.7 \%$ in localization with additional portable gamma camera imaging. These authors also report a slight increase in the number of patients with 3 or more sentinel lymph nodes, although not statistically significant (5).

\section{CONCLUSION}

The limitations of this novel method are application of two different devices (gamma probe and portable gamma camera), which may cause some increase in the duration of the surgical procedure. This method may be more critical in radionuclide lesion localization for breast lesions and residue removal for thyroid carcinomas. 
The combined usage of blue dye, preoperative gamma camera imaging, intraoperative gamma probe imaging, and portable gamma camera revealed complementary results in this case for the identification of sentinel lymph nodes. Portable gamma camera may also add information in more complicated cases for sentinel lymph node identification.

Video: Exploration of the lymph node in left axilla by portable gamma camera

Informed Consent: Written informed consent was obtained patient who participated in this study.

Peer-review: Externallypeer-reviewed.

Author Contributions: Concept - Z.P.K., P.P.Ö.K., M.B., T.A.; Design Z.P.K., P.P.Ö.K., M.B., T.A.; Supervision - T.A.; Resource - Z.P.K., P.P.Ö.K., M.B., T.A.; Materials - Z.P.K., P.P.Ö.K., M.B., T.A.; Data Collection and/or Processing - Z.P.K., P.P.Ö.K, M.B., T.A.; Analysis and/or Interpretation - Z.P.K., P.P.Ö.K., M.B., T.A.; Literature Search - Z.P.K., P.P.Ö.K., M.B., T.A.; Writing Manuscript - Z.P.K., P.P.Ö.K., M.B., T.A.; Critical Reviews - Z.P.K., P.P.Ö.K., M.B., T.A.

Conflict of Interest: No conflict of interest was declared by the authors.

Financial Disclosure: The authors declared that this study has received no financial support.

\section{REFERENCES}

1. Bao J, Donovan C, Chung A, Giuliano AE. The staging value of sentinel lymph node biopsy for breast cancer: translating pathologic findings to clinical practice. Chin Clin Oncol 2016; 5: 36. [CrossRef]

2. Lee JH. Radionuclide methods for breast cancer staging. Semin Nucl Med 2013; 43: 294-298. [CrossRef]

3. Arslan G, Altintoprak KM, Yirgin IK, Atasoy MM, Celik L. Diagnostic accuracy of metastatic axillary lymph nodes in breast MRI. Springerplus 2016; 5: 735. [CrossRef]

4. Nowikiewicz T, Kurylcio A, Polkowski W, Zegarski W. Imaging methods for the local lymphatic system of the axilla in early breast cancer in patients qualified forsentinel lymph node biopsy. Prz Menopauzalny 2016; 15: 52-55. [CrossRef]
5. Goñi Gironés E, Vicente García F, Serra Arbeloa P, Estébanez Estébanez C, Calvo Benito A, Rodrigo Rincón I, et al. Evaluation of the efficacy of sentinel node detection in breast cancer: chronological course and influence of the incorporation of an intra-operative portable gamma camera. Rev Esp Med Nucl Imagen Mol 2013; 32: 343-349. [CrossRef]

6. Chondrogiannis S, Ferretti A, Facci E, Marzola MC, Rampin L, Tadayyon $\mathrm{S}$, et al. Intraoperative hand-held imaging $\mathrm{Y}$-camera for sentinel node detection in patients with breastcancer: feasibility evaluation and preliminary experience on 16 patients. ClinNucl Med 2013; 38: e132-136. [CrossRef]

7. Rasilla JM, Arboniés JC, Bolton RD, Pereyra LI, Andía GS, Soriano $A P$, et al. SPECT-CT in sentinel node detection in patients with melanoma. Rev Esp Med Nucl 2009; 28: 229-234.

8. Silverio AM, McRae MC, Ariyan S, Narayan D. Management of the difficult sentinel lymph node in patients with primary cutaneous melanoma. Ann PlastSurg 2009; 62: 564-569. [CrossRef]

9. Vidal-Sicart S, Paredes P, Zanón G, Pahisa J, Martinez-Román S, Caparrós $\mathrm{X}$, et al. Added value of intraoperative real-time imaging in searches for difficult-to-locate sentinel nodes. J Nucl Med 2010; 51: 1219-1225. [CrossRef]

10. Soluri A, Massari R, Trotta C, Tofani A, Di Santo G, Di Pietro B, et al. Small field of view, high-resolution, portable $\gamma$-camera for axillary sentinel node detection. Nucllnstrum Methods Phys Res A 2006; 569: 273-276. [CrossRef]

11. Vermeeren L, Valdés Olmos RA, Klop WM, Balm AJ, van den Brekel MW. A portable gamma-camera for intraoperative detection of sentinel nodes in the head and neck region. J Nucl Med 2010; 51: 700-703. [CrossRef]

12. Vidal-Sicart $\mathrm{S}$, Vermeeren $\mathrm{L}$, Solà $\mathrm{O}$, Paredes $\mathrm{P}$, Valdés-Olmos RA. The use of a portable gamma camera for preoperative lymphatic mapping: a comparison with a conventional gamma camera. Eur J Nucl Med Mol Imaging 2011; 38: 636-641. [CrossRef]

13. Cardona-Arboniés J, Mucientes-Rasilla J, Moreno Elola-Olaso A, Salazar-Andía G, Prieto-Soriano A, Chicharo de Freitas J, et al. Contribution of the portable gamma camera to detect the sentinel node in breast cancer during surgery. Rev Esp Med Nucl Imagen Mol 2012; 31: 130-134. [CrossRef]

14. Cardona-Arboniés J, Mucientes-Rasilla J, Moreno Elola-Olaso A, Salazar-Andía G, Prieto-Soriano A, Chicharo de Freitas J, et al. Contribution of the portable gamma camera to detect the sentinel node in breast cancer during surgery. Rev Esp Med Nucl Imagen Mol 2012; 31: 130-4. [CrossRef] 